\title{
Arterial bleeding after endoscopic papillary large balloon dilation without endoscopic sphincterotomy for bile duct stones successfully treated by endoscopic hemostatsis
}

Kei Ito*, Shinsuke Koshita, Yoshihide Kanno, Takahisa Ogawa, and Kaori Masu

Department of Gastroenterology, Sendai City Medical Center, Sendai, Japan

\section{Case report}

A 71 years old man was referred to our department due to acute cholangitis. He had a history of endoscopic sphincterotomy (EST) and removal for bile duct stones. CT revealed multiple stones in the markedly dilated bile duct. Biliary cannulation using a conventional catheter was difficult due to a stenosis of the orifice. After successful wire-guided cannulation, endoscopic papillary large balloon dilation (EPLBD) was

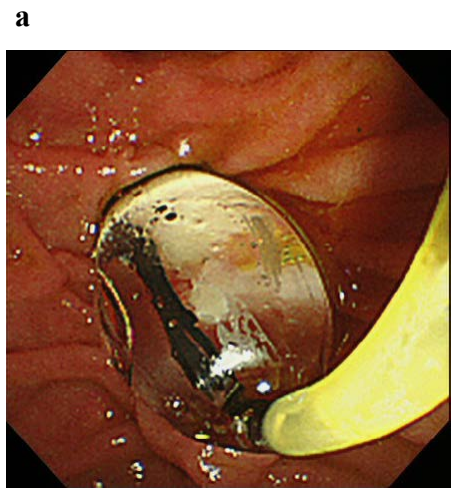

b

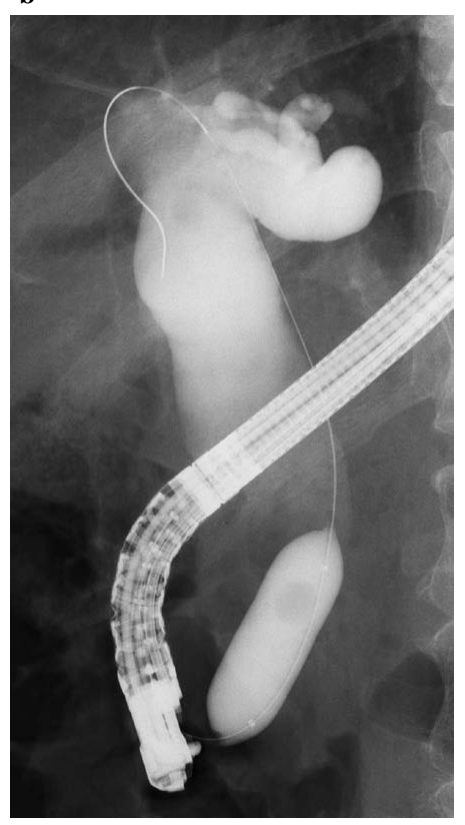

Figure 1. (a, duodenoscopy; b, cholangiography) EPLBD using a balloon catheter was performed.

performed with a balloon catheter (GIGA balloon, Century Medical, Inc., Tokyo, Japan). The orifice was dilated up to $17 \mathrm{~mm}$ in diameter. Massive arterial bleeding occurred immediately after gradual balloon deflation. The balloon was re-inflated. Although balloon hemostasis continued for 15 minutes, arterial bleeding at the terminal end of the bile duct was observed. Local injection of hypertonic saline epinephrine (HSE, $0.5 \mathrm{~mL} \times 10$ times) was successfully performed for hemostasis. Next day, duodenoscopy revealed a vessel, which was cauterized using argon plasma coagulation (APC) with a power setting of $40 \mathrm{~W}$ and a gas flow of $0.4 \mathrm{~L} / \mathrm{min}$. Bile duct stones were removed with a basket/ balloon catheter three days later, and the patients was discharged.

EPLBD has been developed for the treatment of difficult cases such as large/multiple stones [1,2]. This method enables achievement of a sufficiently large opening of the orifice of the bile duct, which helps decrease the difficulty in stone removal and reduces the procedure time [3]. Bleeding after EST followed by EPLBD has been reported to occur in 5.9\% [4]. The bleeding of EPLBD itself is thought to be extremely rare [4,5]. Local injection of HSE is useful for hemostasis after EST [6]. Although placement of a covered metal stent has been also reported to be effective for hemostasis after EPLBD following EST, the methodology has not been established. The present case can demonstrate the usefulness of HSE injection and APC for hemostasis after EPLBD without EST (Figures 1 and 2).

a

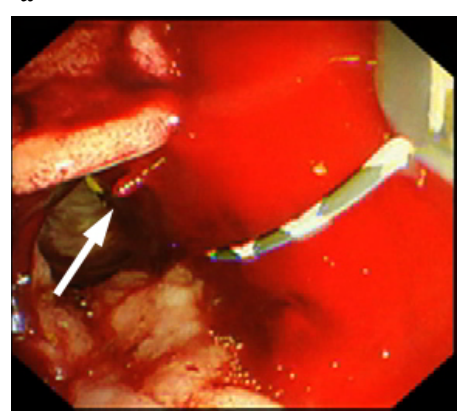

Figure 2. (duodenoscopy)

Arterial bleeding was observed at the terminal end of the bile duct (a, arrow). Next day, duodenoscopy revealed a vessel (b, arrow), which was cauterized using APC.

Correspondence to: Dr. Kei Ito, Department of Gastroenterology, Sendai City Medical Center, 5-22-1, Tsurugaya, Miyagino-ku, Sendai, Miyagi 983-0824, Japan; Tel: +81-22-252-1111; Fax: +81-22-252-9431; E-mail: keiito@openhp.or.jp

Received: January 28, 2017; Accepted: February 18, 2017; Published: February 21,2017 
Ito K (2017) Arterial bleeding after endoscopic papillary large balloon dilation without endoscopic sphincterotomy for bile duct stones successfully treated by endoscopic hemostatsis

\section{References}

1. Ersoz G, Tekesin O, Ozutemiz AO, Gunsar F (2003) Biliary sphincterotomy plus dilation with a large balloon for bile duct stones that are difficult to extract. Gastrointest Endosc 57: 156-159.[Crossref]

2. Minami A, Hirose S, Nomoto T, Hayasaka S (2007) Small sphincterotomy combined with papillary dilation with large balloon permits retrieval of large stones without mechanical lithotripsy. World J Gastroenterol 13: 2179-2182. [Crossref]

3. Itoi T, Itokawa F, Sofuni A, Kurihara T, Tsuchiya T, et al. (2009) Endoscopic sphincterotomy combined with large balloon dilation can reduce the procedure time and fluoroscopy time for removal of large bile duct stones. Am J Gastroenterol 104: 560-565. [Crossref]
4. Park SJ, Kim JH, Hwang JC, Kim HG, Lee DH, et al. (2013) Factors predictive of adverse events following endoscopic papillary large balloon dilation: results from a multicenter series. Dig Dis Sci 58: 1100-1109. [Crossref]

5. Lee TH, park SH, Lee CK, Chung IK, Kim SJ, et al. (2009) Life-threatening hemorrhage following large-balloon Endoscopic papillary dilation successfully treated with angiographic embolization. Endoscopy 41 (Suppl 2): E241-242. [Crossref]

6. Sakai Y, Tsuyuguchi T, Sugiyama H, Nishikawa T, Kurosawa J, et al. (2013) Hypertonic saline-epinephrine local injection therapy for post-endoscopic sphincterotomy bleeding: removal of blood clots using pure ethanol local injection. Surg Laparosc Percutan Tech 23: 156-159. [Crossref]

Copyright: (C2017 Ito K. This is an open-access article distributed under the terms of the Creative Commons Attribution License, which permits unrestricted use, distribution, and reproduction in any medium, provided the original author and source are credited. 